OPEN ACCESS

Edited by:

Nora V. Butta,

University Hospital La Paz Research Institute (IdiPAZ), Spain

Reviewed by:

Aiming Pang,

Chinese Academy of Medical Sciences and Peking Union Medical

College, China

Ching-Ying Kuo,

National Taiwan University, Taiwan

*Correspondence:

Yuanjun Wu wuyuanjun199@126.com

Specialty section:

This article was submitted to

Hematology,

a section of the journa

Frontiers in Medicine

Received: 10 June 2021

Accepted: 21 July 2021

Published: 12 August 2021

Citation:

Wu Y, Wu Y, Ji Y, Liang J, He Z, Liu Y, Tang $L$ and Guo $G$ (2021) Case Report: Drug-Induced Immune Haemolytic Anaemia Caused by

Cefoperazone-Tazobactam

Sulbactam Combination Therapy.

Front. Med. 8:697192.

doi: 10.3389/fmed.2021.697192

\section{Case Report: Drug-Induced Immune Haemolytic Anaemia Caused by Cefoperazone-Tazobactam/ Sulbactam Combination Therapy}

\author{
Yuanjun $\mathrm{Wu}^{1 *}$, Yong $\mathrm{Wu}^{2}$, Yanli $\mathrm{Ji}^{3}$, Jiajie Liang ${ }^{4}$, Ziyi He ${ }^{5}$, Yanhui Liu ${ }^{4}, \mathrm{Li} \mathrm{Tang}^{6}$ and \\ Ganping Guo ${ }^{1}$
}

${ }^{1}$ Department of Blood Transfusion, Dongguan Maternal and Child Health Hospital, Dongguan, China, ${ }^{2}$ Department of Blood Transfusion, Dongguan Tungwah Hospital, Dongguan, China, ${ }^{3}$ Institute of Clinical Blood Transfusion, Guangzhou Blood Center, Guangzhou, China, ${ }^{4}$ Dongguan Institute of Reproductive and Genetic Research, Dongguan Maternal and Child Health Hospital, Dongguan, China, ${ }^{5}$ Department of Transfusion Research, Dongguan Blood Center, Dongguan, China,

${ }^{6}$ Department of Research, Dongguan Maternal and Child Health Hospital, Dongguan, China

There has previously been a report of a patient developing haemolytic anaemia following exposure to cefoperazone. Another case has been reported involving the detection of cefoperazone-dependent antibodies in the absence of immune haemolytic anaemia. To date, no serological evidence has been reported to suggest that cefoperazone can lead to drug-induced immune haemolytic anaemia (DIIHA). This report aims to fill these gaps in knowledge by describing a case of DIIHA caused by cefoperazone-dependent antibodies. A 59-year-old man developed fatal haemolytic anaemia while receiving cefoperazone-tazobactam or cefoperazone-sulbactam for the treatment of a lung infection that occurred after craniocerebral surgery. This eventually led to renal function impairment. Prior to the discontinuation of cefoperazone treatment, the patient showed strong positive (4+) results for both anti-lgG and anti-C3d direct antiglobulin test (DAT), while cefoperazone-dependent IgM and IgG antibodies were detected. The patient's plasma and O-type RBCs were incubated with tazobactam or sulbactam solution at $37^{\circ} \mathrm{C}$ for $3 \mathrm{~h}$, the results of DAT for anti-lgG and anti-C3d were both positive. Forty-three days after the discontinuation of cefoperazone, the results of DAT for anti-lgG and anti-C3d were negative. Meanwhile incubation of the patient's fresh serum and his own RBCs with cefoperazone at $37^{\circ} \mathrm{C}$, gave rise to mild haemolysis, and the results of DAT for both anti-IgG and anti-C3d were positive. It is suggested that cefoperazone-dependent antibodies can activate complement, and the non-immunologic protein adsorption effect of tazobactam or sulbactam can enhance lgG and complement binding to RBCs. This may promote the formation of immunocomplexes and complement activation, thereby aggravating haemolysis.

Keywords: cefoperazone, tazobactam, sulbactam, cefoperazone-dependent antibodies, nonimmunologic protein adsorption (NIPA), druginduced immune hemolytic anaemia (DIIHA), direct antiglobulin test (DAT) 


\section{INTRODUCTION}

Drug-induced immune haemolytic anaemia (DIIHA) is believed to be caused by damage to red blood cells (RBCs), through drug-induced (drug-dependent and -independent) antibodies or non-immunologic protein adsorption (NIPA) (1-3). Almost all patients with DIIHA present severe anaemia caused by drug-induced antibodies (2). NIPA produces a positive direct antiglobulin test (DAT) result, and causes slow, covert, mild haemolysis (3-5). Approximately 140 drugs have been reported to cause DIIHA via drug-induced antibodies, and approximately 10 via NIPA (2-12).

Cefoperazone is a third-generation cephalosporin (13). Novaretti et al. reported that among 41 DAT-positive hospitalized patients with haematological disorders, serological tests found one to possess cefoperazone-dependent antibodies. However, this patient did not have any manifestations of immune haemolytic anaemia (14). Tazobactam and sulbactam are irreversible competitive $\beta$-lactamase inhibitors that can elucidate NIPA, leading to positive DAT results and elusive mild haemolysis $(3,4)$. Tazobactam or sulbactam used in combination with cephalosporins can improve the antibacterial effect; cefoperazone is commonly used in combination with tazobactam or sulbactam in the treatment of bacterial infections (15). Ling et al. reported that a 60-year-old woman, who had developed a lung infection following left atrial myxoma resection, developed haemolytic anaemia and tested positive in DAT for anti-C3d while being treated with cefoperazone and sulbactam (16). Cefoperazonesulbactam combination therapy was thought to have induced DIIHA, but no serological tests were performed to detect druginduced antibodies.

Here, we report a 59-year-old male who experienced severe haemolytic anaemia, along with liver and kidney dysfunction, while being administered an intravenous infusion of cefoperazone-tazobactam or cefoperazone-sulbactam for the treatment of pulmonary infection following cerebral haemorrhage and cerebral hernia surgery. Cefoperazonedependent antibodies were detected in the plasma by serologic testing. To the best of our knowledge, this is the first reported case of DIIHA and renal failure caused by cefoperazone-dependent antibodies to be confirmed by serological methods. Combining the clinical evidence with immunological, biochemical and in vitro findings suggesting that the NIPA effect of tazobactam and sulbactam may promote the formation of immune complexes of cefoperazone-dependent antibodies with cefoperazone-coated RBCs in vivo; this would, in turn, activate the complement system, exacerbating haemolysis.

\section{CASE DESCRIPTION}

A 59-year-old male received cefoperazone-tazobactam (2:1) by intravenous infusion $(2 \mathrm{~g}$ dose administered every $8 \mathrm{~h}$; total

Abbreviations: DIIHA, drug-induced immune haemolytic anaemia; RBC, red blood cell; RBCs, red blood cells; NIPA, non-immunologic protein adsorption; DAT, direct antiglobulin test; TPE, therapeutic plasma exchange; Hb, haemoglobin; LRBCs, leukocyte-reduced red blood cells; WRBCs, washed red blood cells; LDH, lactate dehydrogenase; BUN, blood urea nitrogen; G6PD, Glucose-6-phosphate dehydrogenase; PBS, phosphate buffer solution; 2ME, 2-mercaptoethanol.
$48 \mathrm{~g}$ cefoperazone-tazobactam administered through the course of treatment) for the treatment of a pulmonary infection and pleural effusion, which occurred following surgery for cerebral haemorrhage and cerebral hernia. Seven days after the start of treatment, yellowing of the patient's sclera was observed. On day 8, yellowing of the skin succeeded. Cefoperazone-tazobactam was discontinued and replaced with the more potent antibiotic, meropenem for the treatment of the severe pulmonary infection. The next day, therapeutic plasma exchange (TPE) was performed and bilirubin adsorption therapy was administered to address the aggravation of systemic jaundice and hyperbilirubinemia; bilirubin levels decreased significantly following this treatment. Four days later, the patient's haemoglobin $(\mathrm{Hb})$ levels dropped to $61 \mathrm{~g} / \mathrm{L}$; a leukocyte-reduced red blood cells (LRBCs) infusion was administered, and the $\mathrm{Hb}$ levels rose to $103 \mathrm{~g} / \mathrm{L}$.

Treatment with meropenem for 12 days significantly alleviated the lung infection, and therapy was switched to the less potent cefoperazone-sulbactam (2:1) combination ( $3 \mathrm{~g}$ dose administered every $8 \mathrm{~h}$; total $21 \mathrm{~g}$ cefoperazonesulbactam administered through the course of treatment). TPE and bilirubin adsorption therapy were used again to address the reappearance of hyperbilirubinemia. Meropenem and levofloxacin were administered for 7 days.

On the 32nd day of hospitalization, the patient's condition improved and cefoperazone-sulbactam combination therapy was resumed $(3 \mathrm{~g}$ dose administered every $8 \mathrm{~h}$; total $24 \mathrm{~g}$ cefoperazone-sulbactam administered through the course of treatment). After 2 days, yellowing of the skin of the whole body was observed; after 3 days, antibiotic therapy was switched back to meropenem, and the yellow skin color faded.

Following this, computed tomography and pathological examinations revealed a malignant tumor in the left lobe of the patient's liver. On day 63 of hospitalization, the patient was subjected to superselective hepatic angiography and chemoembolization. After the operation, intravenous cefoperazone-sulbactam therapy was resumed at the same dose (total dose of $57 \mathrm{~g}$ administered during this stage of treatment). Three days after restarting cefoperazone-sulbactam administration, the patient's urine appeared brown, and the skin yellowish. The situation gradually aggravated. On day 4, the patient experienced dyspnoea, and metabolic acidosis; serum complement C3 and C4 levels decreased to $0.493 \mathrm{~g} / \mathrm{L}$ (normal: $0.79-1.52 \mathrm{~g} / \mathrm{L})$ and $0.128 \mathrm{~g} / \mathrm{L}(0.16-0.38 \mathrm{~g} / \mathrm{L})$, respectively. The patient was diagnosed with haemolytic crisis and transferred to the intensive care unit, where he was given blood volume supplementation, alkalized urine, dopamine, epinephrine and an intravenous infusion of methylprednisolone $1,000 \mathrm{mg}$. Hepatic and renal impairment occurred on day 5. Continuous renal replacement therapy was initiated on day 6 . Blood exchange therapy was also administered. On day 8 , TPE was performed and RBC replacement therapy was administered. Cefoperazonesulbactam combination therapy was discontinued because of the suspected haemolytic association. On day 9, TPE was performed and LRBCs were infused. On day 10, washed red blood cells (WRBCs) were infused. The liver function, bilirubin and lactate dehydrogenase (LDH) then gradually returned to normal levels, and $\mathrm{Hb}$ stabilized at the baseline level. Blood urea nitrogen (BUN), creatinine levels, and urine output returned to 

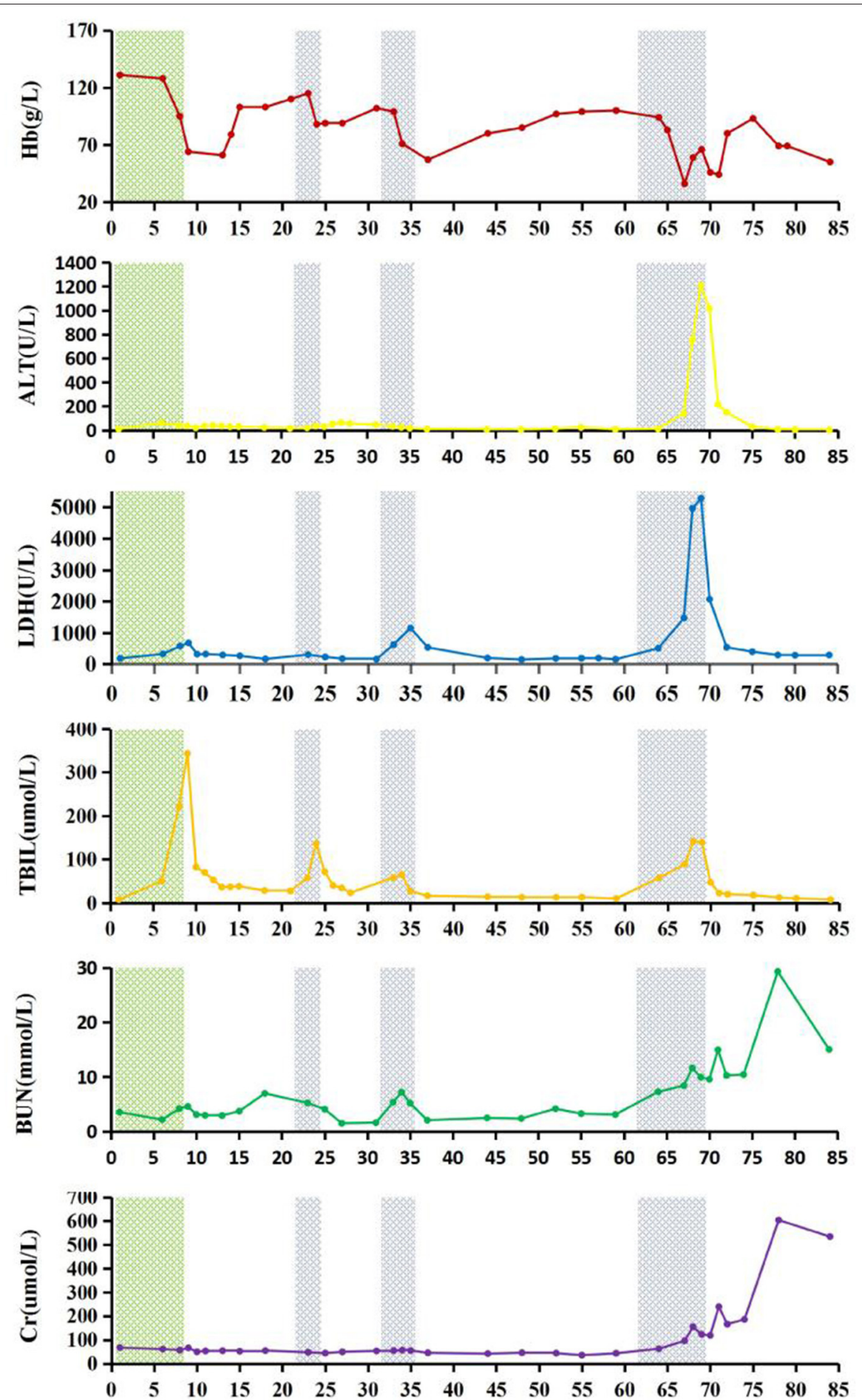

\section{Cefoperazone-tazobactam Treatment $\quad 888888$ Cefoperazone-sulbactam Treatment}

FIGURE 1 | Changes in haemoglobin (Hb), alanine transaminase (ALT), lactate dehydrogenase (LDH), total bilirubin (TBIL), blood urea nitrogen (BUN), and creatinine (Cr) levels during cefoperazone-tazobactam and cefoperazone-sulbactam treatment. On the 9th day of hospitalization, therapeutic plasma exchange (TPE) with $2,100 \mathrm{~mL}$ of frozen plasma and bilirubin adsorption treatment were performed. On days 13 and 14, leukocyte-reduced red blood cells (LRBCs) prepared from $1,200 \mathrm{~mL}$ of whole blood were infused. On day 24 , TPE with $2,000 \mathrm{~mL}$ of frozen plasma and bilirubin adsorption treatment were performed. On day 67 of hospitalization, $1,050 \mathrm{~mL}$ of frozen plasma and LRBCs prepared from 1,200 mL of whole blood were used for whole blood replacement therapy, and continuous renal replacement therapy was started. On day 69 , TPE was performed using $4,100 \mathrm{~mL}$ of frozen plasma, followed by red blood cell exchange treatment with LRBCs prepared from $1,400 \mathrm{~mL}$ of whole blood. On day 70 , TPE was repeated with $4,000 \mathrm{~mL}$ of frozen plasma, and LRBCs prepared from $400 \mathrm{~mL}$ of whole blood were infused. On the 71st day of hospitalization, washed red blood cells prepared from $800 \mathrm{~mL}$ of whole blood were infused. 
near normal levels 45 days after cefoperazone-sulbactam was discontinued and continuous renal replacement therapy was then ceased.

Glucose-6-phosphate dehydrogenase (G6PD) activity and thalassemia gene screening results were found to be normal. On days 6 and 7 of the 4th course of cefoperazone therapy (during severe haemolysis), and the 6th day after cefoperazone was discontinued, the percentage of reticulocytes of the patient were $0.1,0.3$, and $4.7 \%$, respectively (reference interval $0.5-$ $1.5 \%)$. The dynamics of $\mathrm{Hb}, \mathrm{LDH}$, total bilirubin, alanine transaminase, BUN, creatinine, and cefoperazone-tazobactam and cefoperazone-sulbactam administration are shown in Figure 1. The patient had a history of aneurysm clipping, skull repair, and ventriculoperitoneal shunt placement, but no history of anaemia.

\section{SEROLOGICAL TEST RESULTS}

As described by Leger and co-workers (17, 18), serological analysis including DAT, acid elution test, irregular RBC antibody screening were conducted on the patient's blood samples. Cefoperazone, tazobactam, sulbactam solutions, and the respective drug-coated RBCs were used to detect drug-dependent antibodies. In vitro experiments were conducted to verify the complement activation effect of drug-dependent antibodies, and the NIPA effect of tazobactam and sulbactam.

The results of irregular RBC antibody screening of plasma and acid eluates from the blood samples collected on days 67, 69 (cefoperazone treatment was discontinued), 71, 73, 75, 78, 85, 93, 104,112 , and 123 after hospitalization were all negative. DAT for anti-IgG and anti-C3d of the blood sample collected 2 days prior to the discontinuation of cefoperazone were strongly positive $(4+)$, and gradually weakened for blood samples collected after cefoperazone discontinuation. The results of DAT for antiIgG and anti-C3d became negative 43 and 16 days after the discontinuation of cefoperazone, respectively.

Cefoperazone solution $(1-10 \mathrm{mg} / \mathrm{mL})$ were incubated with $\mathrm{O}$ type WRBCs and plasma collected on days 67, 69 (cefoperazone discontinued), 71, 73, 75, 78, 85, 93, 104, 112, and 123 after the patient's admission, cefoperazone-dependent antibodies were detected in every plasma sample, with the highest titre of 32 .

TABLE 2 | Results of direct antiglobulin tests and cefoperazone-dependent antibody titer tests.

\begin{tabular}{|c|c|c|c|c|}
\hline \multirow{2}{*}{$\begin{array}{l}\text { Hospitalization days } \\
\text { (Days since } \\
\text { discontinuation of } \\
\text { cefoperazone) }\end{array}$} & \multicolumn{2}{|c|}{ DAT } & \multicolumn{2}{|c|}{$\begin{array}{l}1 \mathrm{mg} / \mathrm{mL} \mathrm{CPZ} \text { detected } \\
\mathrm{CPZ} \text {-dependent antibody } \\
\text { titers with Coombs card }\end{array}$} \\
\hline & anti-IgG & anti-C3d & Plasma & $\begin{array}{l}2 \mathrm{ME} \text { treated } \\
\text { plasma }\end{array}$ \\
\hline $67(-2)$ & $4+$ & $4+$ & 16 & 16 \\
\hline $69(0)$ & $4+$ & $3+$ & 8 & 8 \\
\hline 71 (2) & $4+$ & $3+$ & 8 & 8 \\
\hline $73(4)$ & $2+$ & $3+$ & 16 & 16 \\
\hline 75 (6) & $2+$ & $2+$ & 32 & 32 \\
\hline 78 (9) & $2+$ & $1+$ & 16 & 16 \\
\hline 85 (16) & $2+$ & - & 8 & NT \\
\hline 93 (24) & $2+$ & - & 8 & NT \\
\hline 104 (35) & $1+$ & - & 16 & NT \\
\hline $112(43)$ & - & - & 16 & NT \\
\hline $123(54)$ & - & - & 8 & NT \\
\hline
\end{tabular}

DAT, direct antiglobulin test; $C P Z$, cefoperazone; $C P Z-R B C s$, cefoperazone-coated red blood cells; 2ME, 2-mercaptoethanol; NT, not detected.

+ , strong; - negative.

TABLE 1 | Results of drug-dependent antibody tests of blood samples collected 2 days prior to the discontinuation of cefoperazone treatment.

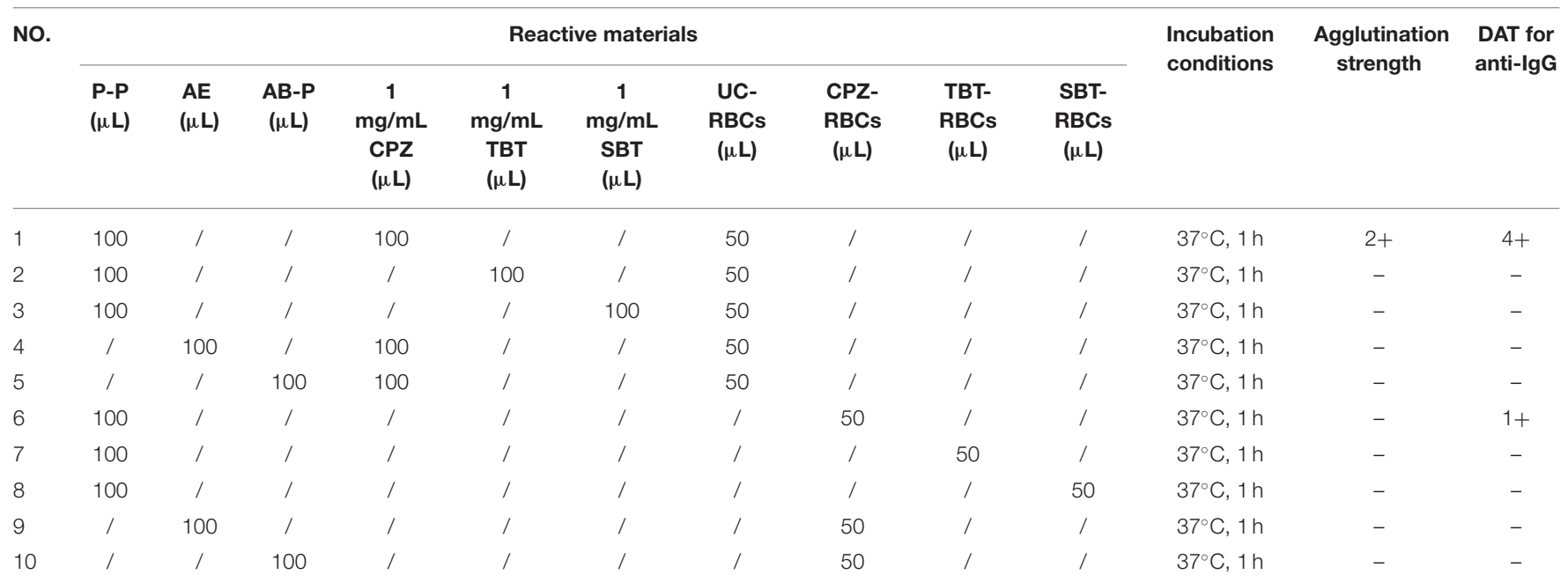

$P$-P, patient's plasma; $A E$, acid eluate; $A B-P, A B$-type plasma with negative antibody screening test result; $C P Z$, cefoperazone; TBT, tazobactam; SBT, sulbactam; UC-RBCs, uncoated red blood cells; CPZ-RBCs, cefoperazone-coated red blood cells; TBT-RBCs, tazobactam-coated red blood cells; SBT-RBCs, sulbactam-coated red blood cells; DAT, direct antiglobulin test. +, strong; -, negative. 
While the patient's plasma was incubated with cefoperazonecoated RBCs at $37^{\circ} \mathrm{C}$ for $1 \mathrm{~h}$, cefoperazone-dependent antibodies were also detected, but the highest titre was only 1 . Therefore, cefoperazone-coated RBCs are not suitable for the detection of cefoperazone-dependent antibodies. Tazobactam- or sulbactamrelated drug-dependent antibodies were not detected in any of the blood samples. Details of drug-dependent antibody testing of the patient's blood sample collected on the 67th day of admission ( 2 days prior to the cessation of cefoperazone treatment) are shown in Table 1.

We treated the plasma with 2-mercaptoethanol (2ME) to cleave the IgM to identify the Ig type of cefoperazonedependent antibodies. The patient's untreated plasma samples were incubated with $1 \mathrm{mg} / \mathrm{mL}$ cefoperazone and O-type RBCs at $37^{\circ} \mathrm{C}$ for $1 \mathrm{~h}$; agglutination was observed by centrifugation in test tubes or in a Coombs test card. Plasma treated with $2 \mathrm{ME}$ was incubated with $1 \mathrm{mg} / \mathrm{mL}$ cefoperazone and O-type RBCs at $37^{\circ} \mathrm{C}$ for $1 \mathrm{~h}$; no agglutination was observed by centrifugation in test tubes, but was observed in the Coombs test card. However, the titres of cefoperazone-dependent antibodies detected by the Coombs test card in untreated plasma and 2ME-treated plasma were similar. The results suggest that the patient's plasma contained both IgM and IgG cefoperazone-dependent antibodies, with the IgG type being predominant. Table 2 shows the changes in the DAT results and the titres of cefoperazonedependent antibodies in the patient monitored over time.

Plasma (with or without $2 \mathrm{ME}$ treatment) from blood samples collected 2 days prior to the discontinuation of cefoperazonesulbactam treatment and O-type WRBCs was incubated with cefoperazone, tazobactam, or sulbactam (the final concentration of each drug was $1 \mathrm{mg} / \mathrm{mL}$ ) at $37^{\circ} \mathrm{C}$, to verify the NIPA effect of tazobactam or sulbactam whether promoted the binding of antibodies and complement to RBCs, and the results were certain. Detailed results of the in vitro control tests are shown in Table 3.

After the discontinuation of cefoperazone-sulbactam therapy for 43 days, the results of DAT for both anti-IgG and antiC3d were negative, and the cefoperazone-dependent antibody titre was 16. The patient's fresh serum and his own RBCs were incubated with cefoperazone, tazobactam, or sulbactam solution at $37^{\circ} \mathrm{C}$, to confirm that cefoperazone-dependent antibodies can cause complement activation. The results showed that cefoperazone-dependent antibodies can cause complement activation and mild haemolysis in vitro. Detailed results of the in vitro control test are shown in Table 4.

\section{DISCUSSIONS}

The patient developed severe haemolytic anaemia, hyperbilirubinemia, and elevated LDH levels during the cefoperazone-tazobactam/sulbactam combination therapy. The situation worsened and eventually progressed to haemolytic crisis and acute liver and kidney damage. Retrospective analysis revealed that the changes in the patient's $\mathrm{Hb}, \mathrm{LDH}$, total bilirubin, alanine transaminase, BUN, and creatinine levels were highly correlated with cefoperazone-tazobactam or cefoperazonesulbactam administration. When the patient developed haemolytic crisis during the third course of cefoperazonesulbactam therapy, the physician considered the possibility of DIIHA. At this time, DAT was performed using the patient's blood samples which were stored in the clinical laboratory for routine testing, and the results for anti-IgG and anti-C3d were strong positives (4+). However, the agglutination intensity of DAT for anti-IgG and anti-C3d gradually decreased after treatment with cefoperazone-sulbactam was discontinued,

TABLE 3 | In vitro validation of non-immunologic protein adsorption caused by tazobactam and sulbactam.

\begin{tabular}{|c|c|c|c|c|c|c|c|c|c|c|c|c|}
\hline \multirow[t]{2}{*}{ NO. } & \multicolumn{8}{|c|}{ Reactive materials } & \multirow{2}{*}{$\begin{array}{l}\text { Incubation } \\
\text { conditions }\end{array}$} & \multirow{2}{*}{$\begin{array}{l}\text { Agglutination } \\
\text { or haemolysis }\end{array}$} & \multicolumn{2}{|c|}{ DAT } \\
\hline & $\begin{array}{c}\text { O-WRBCs } \\
(\mu L)\end{array}$ & $\begin{array}{l}\text { P-P } \\
(\mu L)\end{array}$ & $\begin{array}{l}\text { 2ME PP } \\
(\mu L)\end{array}$ & $\begin{array}{c}\text { AB-P } \\
(\mu L)\end{array}$ & $\begin{array}{l}\text { PBS } \\
(\mu L)\end{array}$ & $\begin{array}{c}40 \mathrm{mg} / \mathrm{mL} \\
\mathrm{CPZ} \\
(\mu \mathrm{L})\end{array}$ & $\begin{array}{c}40 \mathrm{mg} / \mathrm{mL} \\
\text { TBT } \\
(\mu \mathrm{L})\end{array}$ & $\begin{array}{c}40 \mathrm{mg} / \mathrm{mL} \\
\text { SBT } \\
(\mu L)\end{array}$ & & & anti-IgG & anti-C3d \\
\hline 1 & 40 & 350 & / & / & / & 10 & / & / & $37^{\circ} \mathrm{C}, 3 \mathrm{~h}$ & $3+, \mathrm{NH}$ & NT & NT \\
\hline 2 & 40 & 350 & / & / & / & / & 10 & / & $37^{\circ} \mathrm{C}, 3 \mathrm{~h}$ & $\mathrm{NA}, \mathrm{NH}$ & $4+$ & \pm \\
\hline 3 & 40 & 350 & / & / & / & / & / & 10 & $37^{\circ} \mathrm{C}, 3 \mathrm{~h}$ & $\mathrm{NA}, \mathrm{NH}$ & $4+$ & \pm \\
\hline 4 & 40 & / & 350 & / & / & 10 & / & / & $37^{\circ} \mathrm{C}, 3 \mathrm{~h}$ & $\mathrm{NA}, \mathrm{NH}$ & $4+$ & $1+$ \\
\hline 5 & 40 & / & 350 & / & / & / & 10 & / & $37^{\circ} \mathrm{C}, 3 \mathrm{~h}$ & $\mathrm{NA}, \mathrm{NH}$ & $4+$ & \pm \\
\hline 6 & 40 & / & 350 & / & / & / & / & 10 & $37^{\circ} \mathrm{C}, 3 \mathrm{~h}$ & $\mathrm{NA}, \mathrm{NH}$ & $4+$ & \pm \\
\hline 7 & 40 & 350 & / & / & 10 & / & / & / & $37^{\circ} \mathrm{C}, 3 \mathrm{~h}$ & $\mathrm{NA}, \mathrm{NH}$ & - & - \\
\hline 8 & 40 & / & / & / & 350 & 10 & / & / & $37^{\circ} \mathrm{C}, 3 \mathrm{~h}$ & $\mathrm{NA}, \mathrm{NH}$ & - & - \\
\hline 9 & 40 & / & / & 350 & / & 10 & / & / & $37^{\circ} \mathrm{C}, 3 \mathrm{~h}$ & $\mathrm{NA}, \mathrm{NH}$ & - & - \\
\hline 10 & 40 & / & / & 350 & / & / & 10 & / & $37^{\circ} \mathrm{C}, 3 \mathrm{~h}$ & $\mathrm{NA}, \mathrm{NH}$ & $4+$ & - \\
\hline 11 & 40 & / & / & 350 & I & / & I & 10 & $37^{\circ} \mathrm{C}, 3 \mathrm{~h}$ & $\mathrm{NA}, \mathrm{NH}$ & $4+$ & - \\
\hline
\end{tabular}

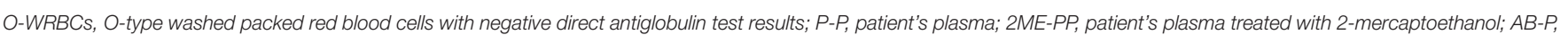

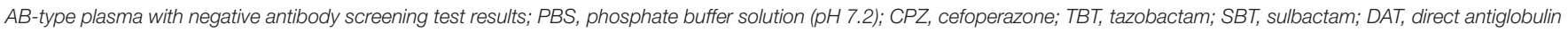

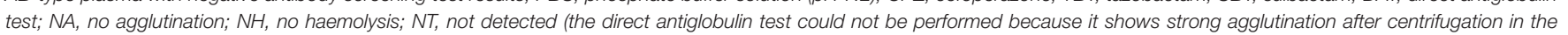
test tube).

+, strong; \pm , slightly strong; -, negative. 


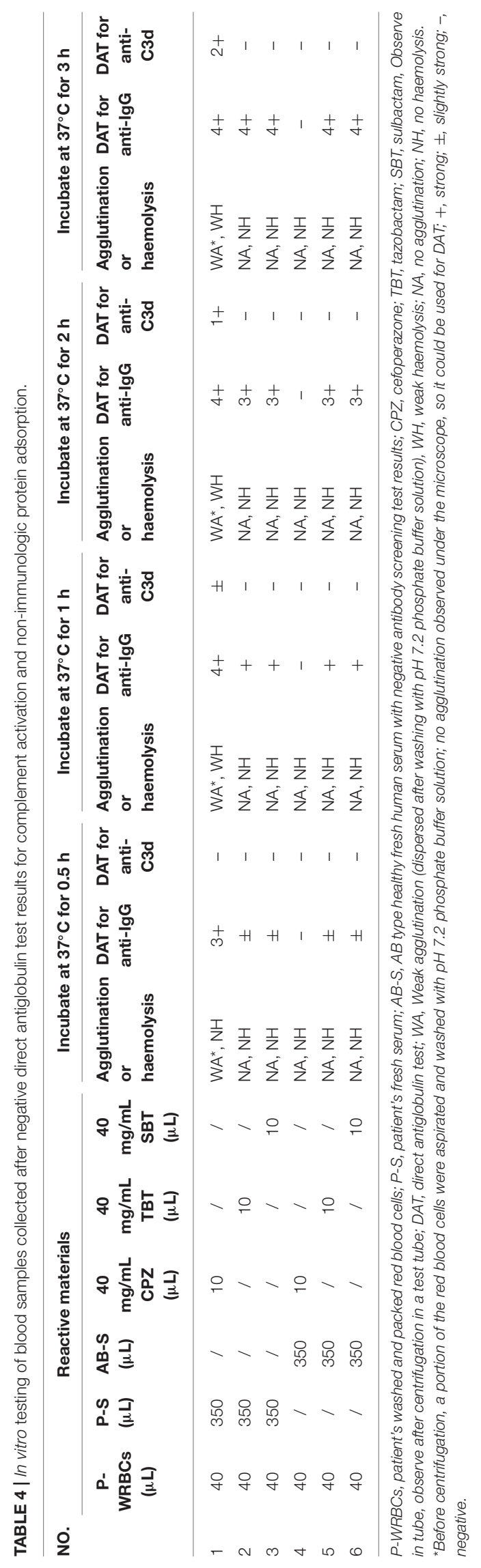

and were negative 43 and 16 days after the discontinuation of cefoperazone-sulbactam therapy, respectively. Irregular RBC antibody screening was repeatedly performed with the patient's plasma and acid eluate, and the results were negative. Cefoperazone-dependent antibodies were detected in the patient's plasma in the presence of cefoperazone solution; no drug-dependent antibodies were detected in the presence of tazobactam or sulbactam solution. Based on the patient's medical history and results of clinical, biochemical, and immunohaematological tests, we ruled out the possibility of haemolytic anaemia caused by G6PD deficiency $(19,20)$ and autoimmune haemolytic anaemia (21-25). The condition was diagnosed as DIIHA caused by cefoperazone-dependent antibodies and the NIPA effect of tazobactam and sulbactam.

Due to the lack of previous reports, the clinical features, immunohaematological characteristics, and treatment and prognosis of DIIHA caused by cefoperazone-dependent antibodies are poorly understood. Also due to the lack of vigilance to the risk of DIIHA caused by cefoperazone and the complexity of the patient's primary disease, haemolysis and jaundice during the repeated use of cefoperazone treatment were initially assumed to be an outcome of relapse of infection. Each time cefoperazone was discontinued and treatment was switched to the higher-level antibiotic meropenem, while the infection was effectively controlled, haemolysis and jaundice were also significantly relieved. This further misled the doctor's judgment, resulting in repeated incidences of cefoperazone-associated haemolysis and DIIHA not being diagnosed in time, ultimately resulting in liver and kidney dysfunction in the patient.

An increase in the reticulocyte count is a characteristic of haemolytic anaemia (23-26). Patients with special haemolytic anaemias, such as hyperhaemolysis syndrome, often exhibit reduced reticulocyte counts. This may be attributed to the potential destruction of reticulocytes during haemolysis. Macrophages in the endothelial system may play a key role in lysis of reticulocytes (27-29). In this patient, the percentage of reticulocytes was significantly below the reference level during the severe haemolysis that followed the fourth cycle of cefoperazone treatment. However, a significant increase in reticulocytes was detected 6 days after the discontinuation of cefoperazone treatment. However, among the reported cases of DIIHA, reticulocyte reduction is rare. The decrease in reticulocytes in this patient may have been a result of other underlying diseases, but it is not yet clear whether cefoperazone-dependent antibodies have a damaging effect on reticulocytes.

Drug-dependent antibodies can be detected by reacting with RBCs in a solution of related drug, or by reacting with drugcoated RBCs. The serological properties of drug-independent antibodies are similar to those of warm autoantibodies; they can be detected by the RBC antibody screening test without the need for related drug solutions or drug-coated RBCs $(1,2,6$, 18). Antibodies induced by different drugs may have different serological characteristics $(2,18)$. Our serological test showed that this patient did not produce drug-independent antibodies, but had produced cefoperazone-dependent IgM and IgG type antibodies. Cefoperazone-dependent antibodies were repeatedly 
tested within 43 days of discontinuation of cefoperazone. The range of antibody titres tested with $1 \mathrm{mg} / \mathrm{mL}$ cefoperazone solution were 8-32, while those tested with cefoperazone-coated RBCs were all only 1 . Therefore, we found that cefoperazone solution, but not cefoperazone-coated RBCs, were suitable for the detection of cefoperazone-dependent antibodies.

The antibody titres that cause DIIHA are usually relatively high $(2,18,30)$. Novaretti et al. previously reported that a patient with cefoperazone-dependent antibodies did not develop immune haemolytic anaemia (14). Therefore, it was assumed that cefoperazone (cefpirome) does not cause haemolytic anaemia (6). In this case, the highest titre of cefoperazonedependent antibodies detected was 32, and very severe DIIHA occurred during treatment with cefoperazone-tazobactam or cefoperazone-sulbactam. The serum complements C3 and C4 were significantly reduced when the patient's haemolysis was most severe, but the DAT for anti-C3d showed a rare strong positive $(4+)$ result. When the patient's plasma and O-type RBCs were incubated with cefoperazone solution at $37^{\circ} \mathrm{C}$, DAT for anti-C3d was positive. At 43 days after the discontinuation of cefoperazone, DAT for both anti-IgG and anti-C3d were negative, and the titre of cefoperazone-dependent antibodies was 16. When the patient's fresh serum and his own RBCs were incubated with cefoperazone solution at $37{ }^{\circ} \mathrm{C}$, DAT for anti-C3d showed a positive $(2+)$ result. The results show that cefoperazone-dependent antibodies exhibit strong complement activation. Novaretti et al. reported that a patient detected to have cefoperazone-dependent antibodies did not experience immune haemolytic anaemia (14); this may have been because the patient did not receive cefoperazone when the antibodies were detected.

When our patient had haemolysis, his plasma and O-type RBCs were incubated with tazobactam or sulbactam solution at $37^{\circ} \mathrm{C}$, and the DAT results for anti-IgG and anti-C3d were positive, suggesting that the NIPA effect of tazobactam or sulbactam may promote the binding of IgG and complements to RBCs. However, NIPA alone does not cause serious DIIHA (3-5). Therefore, while the patient was receiving cefoperazonetazobactam or cefoperazone-sulbactam, the NIPA effect of tazobactam or sulbactam may have promoted the specific binding of cefoperazone-dependent antibodies with the RBCs coated with cefoperazone in the patient's body, promoting the formation of immune complexes and complement activation. This eventually led to the aggravation of haemolysis.

There is little evidence for the appropriate course of treatment for DIIHA. It is very important to discontinue the administration of the related drugs in time and provide the right targeted treatment (31). Corticosteroids are widely used in the treatment of DIIHA, but their effectiveness is difficult to be distinguished from the benefits of stopping the use of the causative drug (8, 32). Rituximab, azathioprine, cyclophosphamide, cyclosporine,

\section{REFERENCES}

1. Garratty G. Immune hemolytic anemia associated with drug therapy. Blood Rev. (2010) 24:143-50. doi: 10.1016/j.blre.2010.06.004 danazol, mycophenolate, and IV immunoglobulin are considered effective in the treatment of severe or refractory autoimmune haemolytic anaemia $(23,33)$, but their efficacy in the treatment of DIIHA remains unclear (8). It has been reported that the administration of TPE to patients with severe DIIHA and renal impairment can be effective (8). Our patient experienced recurring haemolytic anaemias associated with cefoperazonetazobactam or cefoperazone-sulbactam, due to delay in diagnosis. During the period, TPE, bilirubin adsorption, blood transfusion, and whole blood replacement were given several times for the treatment of anaemia, liver damage and hyperbilirubinemia. Continuous renal replacement therapy was administered after the occurrence of renal impairment. Clinical monitoring and laboratory test results suggested that these symptomatic treatments were effective. But there was a lack of knowledge about the condition, leading to a delay in diagnosis. Therefore, there is an urgent need to establish guidelines for the diagnosis and treatment of DIIHA.

\section{DATA AVAILABILITY STATEMENT}

The original contributions presented in the study are included in the article/Supplementary Material. Further inquiries can be directed to the corresponding author.

\section{ETHICS STATEMENT}

The studies involving human participants were reviewed and approved by Ethical Committee of Dongguan Maternal and Child Health Hospital. The patients/participants provided their written informed consent to participate in this study.

\section{AUTHOR CONTRIBUTIONS}

YJW, YW, YLJ, and JJL contributed to the conception and design of the study and data analysis. YJW, JJL, ZYH, YHL, and LT prepared the draught and final manuscript. YJW, YW, YLJ, and GPG performed the immunohematological test. All authors listed have made a contribution to the work, and approved it for publication.

\section{FUNDING}

The Key Project of Social and Scientific Development of Dongguan in 2019 (201950715046181). Guangdong basic and Applied Basic Research Fund project (2020B1515120009).

\section{ACKNOWLEDGMENTS}

We thank the patient for participating in this study and agree to use the results of the study for publication.

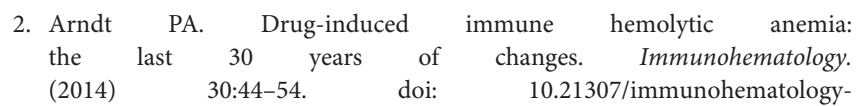
2019-098 
3. Garratty G, Arndt PA. Positive direct antiglobulin tests and haemolytic anaemia following therapy with beta-Lactamase inhibitor containing drugs may be associated with nonimmunologic adsorption of protein onto red blood cells. Br J Haematol. (1998) 100:777-83. doi: 10.1046/j.1365-2141.1998.00615.x

4. Arndt PA, Leger RM, Garratty G. Positive direct antiglobulin tests and haemolytic anaemia following therapy with the beta-lactamase inhibitor, tazobactam, may also be associated with non-immunologic adsorption of protein onto red blood cells. Vox Sang. (2003) 85:53. doi: 10.1046/j.1423-0410.2003.00323.x

5. Arndt P, Garratty G, Isaak E, Bolger M, Lu Q. Positive direct and indirect antiglobulin tests associated with oxaliplatin can be due to drug antibody and/or drug-induced nonimmunologic protein adsorption. Transfusion. (2009) 49:711-8. doi: 10.1111/j.1537-2995.2008.02028.x

6. Garratty G, Arndt PA. Drugs that have been shown to cause druginduced immune hemolytic anemia or positive direct antiglobulin tests: some interesting findings since 2007. Immunohematology. (2014) 30:6679. doi: 10.21307/immunohematology-2019-100

7. Quintanilla-Bordás C, Castro-Izaguirre E, Carcelén-Gadea M, Marín M. The first reported case of drug-induced hemolytic anemia caused by dimethyl fumarate in a patient with multiple sclerosis. Transfusion. (2019) 59:164850. doi: 10.1111/trf.15151

8. Chan M, Silverstein WK, Nikonova A, Pavenski K, Hicks LK. Bendamustine-induced immune hemolytic anemia: a case report and systematic review of the literature. Blood Adv. (2020) 4:1756-9. doi: 10.1182/bloodadvances.2020001726

9. Burgos Pratx L, Santoro D, Coca Mogro B, Valiente VL, Camino P, Scordo W, et al. Etoricoxib-induced immune hemolytic anemia: first case presenting acute kidney failure. Transfusion. (2019) 59:1657-60. doi: 10.1111/trf.15226

10. Lin KS, Win S, Nyein PP. Drug-induced immune hemolytic anemia because of efavirenz: a case report. AIDS. (2020) 34:326-8. doi: 10.1097/QAD.0000000000002425

11. Nguyen TN, Maenulein E, Fihman V, Vinatier I, Klaren JM. Serologic characteristics of oxaliplatin antibodies in 15 patients with drug-induced immune hemolytic anemia. Transfusion. (2021). 61: 1609-16. doi: 10.1111/trf.16360

12. Afra F, Mehri M, Namazi S. Bosentan-induced immune hemolytic anemia in 17 years old man. A case report. Daru. (2021) 29: 2115. doi: 10.1007/s40199-020-00386-1

13. Meng L, Kong L, Wu C, Qi B, Wu X. Pharmacokinetics of cefoperazonesulbactam in plasma and cerebrospinal fluid in patients with intraventricular hemorrhage after external ventricular drains. Eur J Clin Pharmacol. (2020) 76:127-9. doi: 10.1007/s00228-019-02773-3

14. Novaretti MC, Sopeleti CR, Dorlhiac-Llacer PE, Chamone DA. Use of gel microcolumn assay for the detection of drug-induced positive direct antiglobulin tests. J Clin Lab Anal. (2005) 19:219-27. doi: 10.1002/jcla.20081

15. Su J, Guo Q, Li Y, Wu S, Hu F, Xu S, et al. Comparison of empirical therapy with cefoperazone-sulbactam or a carbapenem for bloodstream infections due to ESBL-producing enterobacteriaceae. J Antimicrob Chemother. (2018) 73:3176-80. doi: 10.1093/jac/dky323

16. Zhou L, Bao J, Ma J. Hemolytic anemia and reactive thrombocytosis associated with cefoperazone/sulbactam. Front Pharmacol. (2019) 10:1342. doi: 10.3389/fphar.2019.01342

17. Leger RM, Arndt PA, Ciesielski DJ, Garratty G. False-positive eluate reactivity due to the low-ionic wash solution used with commercial acid-elution kits. Transfusion. (1998) 38:565-72. doi: 10.1046/j.1537-2995.1998.38698326336.x

18. Leger RM, Arndt PA, Garratty G. How we investigate druginduced immune hemolytic anemia. Immunohematology. (2014) 30:85-94. doi: 10.21307/immunohematology-2019-102

19. Horikoshi N, Hwang S, Gati C, Matsui T, Castillo-Orellana C, Raub AG, et al. Long-range structural defects by pathogenic mutations in most severe glucose-6-phosphate dehydrogenase deficiency. Proc Natl Acad Sci USA. (2021) 118:e2022790118. doi: 10.1073/pnas.2022790118
20. Ryan K, Tekwani BL. Current investigations on clinical pharmacology and therapeutics of glucose-6-phosphate dehydrogenase deficiency. Pharmacol Ther. (2020) 222:107788. doi: 10.1016/j.pharmthera.2020. 107788

21. Jäger U, Barcellini W, Broome CM, Gertz MA, Hill A, Hill QA, et al. Diagnosis and treatment of autoimmune hemolytic anemia in adults: recommendations from the first international consensus meeting. Blood Rev. (2020) 41:100648. doi: 10.1016/j.blre.2019.100648

22. Barcellini W. Pitfalls in the diagnosis of autoimmune haemolytic anaemia. Blood Transfus. (2015) 13:3-5. doi: 10.2450/2014.0252-14

23. Go RS, Winters JL, Kay NE. How I treat autoimmune hemolytic anemia. Blood. (2017) 129:2971-979. doi: 10.1182/blood-2016-11-693689

24. Brodsky RA. Warm Autoimmune Hemolytic Anemia. N Engl J Med. (2019) 381:647-54. doi: 10.1056/NEJMcp1900554

25. Wachter F, Archer NM. Autoimmune hemolytic anemia complicated by parvovirus infection. Blood. (2021) 137:1130. doi: 10.1182/blood.20200 09849

26. Phillips J, Henderson AC. Hemolytic anemia: evaluation and differential diagnosis. Am Fam Physician. (2018) 98:354-61.

27. Merrill SA, Brodsky RA, Lanzkron SM, Naik R. A case-control analysis of hyperhemolysis syndrome in adults and laboratory correlates of complement involvement. Transfusion. (2019) 59:3129-39. doi: 10.1111/trf.15445

28. Vagace JM, Cardesa R, Corbacho A, Vázquez T, de la Maya MD, Gonzalez FA, et al. Etiopathological mechanisms and clinical characteristics of hyperhemolysis syndrome in spanishpatients with thalassemia. Ann Hematol. (2016) 95:1419-27. doi: 10.1007/s00277-016-2733-8

29. Wu Y, Ji Y, Dai B, Guo F, Wu Y, He Z, et al. A case of hyperhaemolysis syndrome in a pregnant chinese woman with $\beta$-thalassemia during perinatal transfusion. Transfus Med. (2021) 31:24-9. doi: 10.1111/tme./12748

30. Arndt PA, Garratty G, Brasfield FM, Vemuri SL, Asuncion DJ. Immune hemolytic anemia due to cimetidine: the first example of a cimetidine antibody. Transfusion. (2010) 50:3027. doi: $10.1111 / j .1537-2995.2009 .02447 . x$

31. Hill QA, Stamps R, Massey E, Grainger JD, Provan D, Hill A. British society for haematology guidelines. guidelines on the management of drug-induced immune and secondary autoimmune, haemolytic anaemia. Br J Haematol. (2017) 177:208-20. doi: 10.1111/bjh.14654

32. Garbe E, Andersohn F, Bronder E, Klimpel A, Thomae M, Schrezenmeier $\mathrm{H}$, et al. Drug induced immune haemolytic anaemia in the berlin case-control surveillance study. Br J Haematol. (2011) 154:644-53. doi: 10.1111/j.1365-2141.2011.08784.x

33. Zuercher AW, Spirig R, Baz Morelli A, Kasermann F. IVIG in autoimmune disease - potential next generation biologics. Autoimmun Rev. (2016) 15:7815. doi: 10.1016/j.autrev.2016.03.018

Conflict of Interest: The authors declare that the research was conducted in the absence of any commercial or financial relationships that could be construed as a potential conflict of interest.

Publisher's Note: All claims expressed in this article are solely those of the authors and do not necessarily represent those of their affiliated organizations, or those of the publisher, the editors and the reviewers. Any product that may be evaluated in this article, or claim that may be made by its manufacturer, is not guaranteed or endorsed by the publisher.

Copyright (อ $2021 \mathrm{Wu}, \mathrm{Wu}, \mathrm{Ji}$, Liang, He, Liu, Tang and Guo. This is an open-access article distributed under the terms of the Creative Commons Attribution License (CC $B Y)$. The use, distribution or reproduction in other forums is permitted, provided the original author(s) and the copyright owner(s) are credited and that the original publication in this journal is cited, in accordance with accepted academic practice. No use, distribution or reproduction is permitted which does not comply with these terms. 